\title{
Implementation of an Improvement Cycle using the Competisoft Methodological Framework and the Tutelkan Platform
}

\author{
Rodolfo H. Villarroel \\ Pontificia Universidad Católica de Valparaíso, Escuela de Ingeniería Informática, \\ Valparaíso, Chile, \\ rodolfo.villarroel@ucv.cl
}

\author{
Yessica M. Gómez, Román Gajardo, Oscar Rodríguez \\ Universidad Católica del Maule, Departamento de Computación e Informática, \\ Talca, Chile \\ ygomez@spock.ucm.cl; \{rgajarr1872,orodrim1358\}@alumnos.ucm.cl
}

\begin{abstract}
Formalizing and institutionalizing software processes has become a necessity in recent years requiring the management and enhancement of software production and, at the same time, achieving certification in accordance with international standards. Due to the lack of collaboration tools in Small and Medium-sized Enterprises (SMEs) which could contribute to the improvement of software processes, different proposals have been made to enable these companies to develop and grow. This paper presents the experimental implementation of an improvement cycle in an internal area of a small company, considering the basic profile of the Competisoft process model with support on the Tutelkan platform. Through this experiment, it was noted that Competisoft supplied the basic elements to formalize and institutionalize the processes and that Tutelkan was a good complement to achieving this aim.
\end{abstract}

Keywords: Competisoft, Profle 1, Agil_MANTEMA, Tutelkan, PmCompetisoft, improvement cycle

\section{INTRODUCTION}

Today, companies need to ensure the quality of their software products by constantly improving their processes, using reference models such as the SEI (Software Engineering Institute) and ISO standards (International Organization for Standardization). These models and standards are more often used by large companies because they can deal with the costs and requirements for preparation and assessment. Small and Medium-sized Enterprises SMEs - represent a substantial part of the software industry, but they generally lack well-defined development processes, a fact that implies disordered operation schemes that affect the company as a whole. These companies need to ensure the quality of their products but are unable to invest heavily in terms of both money and time, and more so considering that the investment return is generated over the long-term [1] [3] [10] [13]. This is why initiatives like Competisoft have emerged with the aim of increasing the competitiveness of Latin American software manufacturing SMEs through the creation and distribution of a common methodological framework that, adapted to their specific needs, may become the basis to establishing a mechanism for evaluating and certifying the software industry throughout Latin America [9]. Classification of SMEs is as follows: micro companies (1 to 9 employees), small companies (between 10 and 49 employees) and medium-sized companies (between 50 and 249 employees) [9]. The methodological framework of Competisoft has been put into practice to support the implementation of several cycles of process improvement in different SME software manufacturers in Latin America. This methodological framework consists of a Process Reference Model (MoProSoft) [7], a process assessment method (EvalProSoft) [8] and an improvement model that guides the implementation of the improvement process (PmCompetisoft) [9].

This applied research is the result of collaborative work between the UCM Competisoft research group and a small financial company where a software process improvement cycle was implemented through the use of the Competisoft methodological framework and the support of the Tutelkan web platform.

Three iterations of the improvement cycle were performed. The first one (or improvement mini-cycle) was for the Software Development Process (SD), the second iteration was for the Specific Project Administration (SPA) process, developed in parallel with the first and last iteration for the Software Maintenance (SM) process. This sequence was established in agreement with the heads of the software area and was based on the improvement 
prioritization according to the results of the Initial Process Diagnosis (in relation to the improvement cases, or set of opportunities for improvement, identified for each process). In the assessment the level of capability of each process was measured to identify the improvement opportunities. First, the processes were evaluated based on their constituent attributes (level 1 and level 2), in addition to determining the capability maturity level of the organization. Second, a quantitative analysis was performed (percentage of activity performance in capability levels 1 and 2 for each of the steps defined by the process model) along with a qualitative analysis per process (identifying strengths and improvement opportunities, and also detecting the ratio of activities and tasks of the processes to the roles and artifacts).

This was made possible through the use of assessment tools (questionnaires) and result calculation spreadsheets, in accordance with the process assessment method EvalProSoft. The processes mentioned above are part of the process reference model MoProSoft and the Operation category (OPE), which are also part of the Competisoft basic profile (see Figure 1).

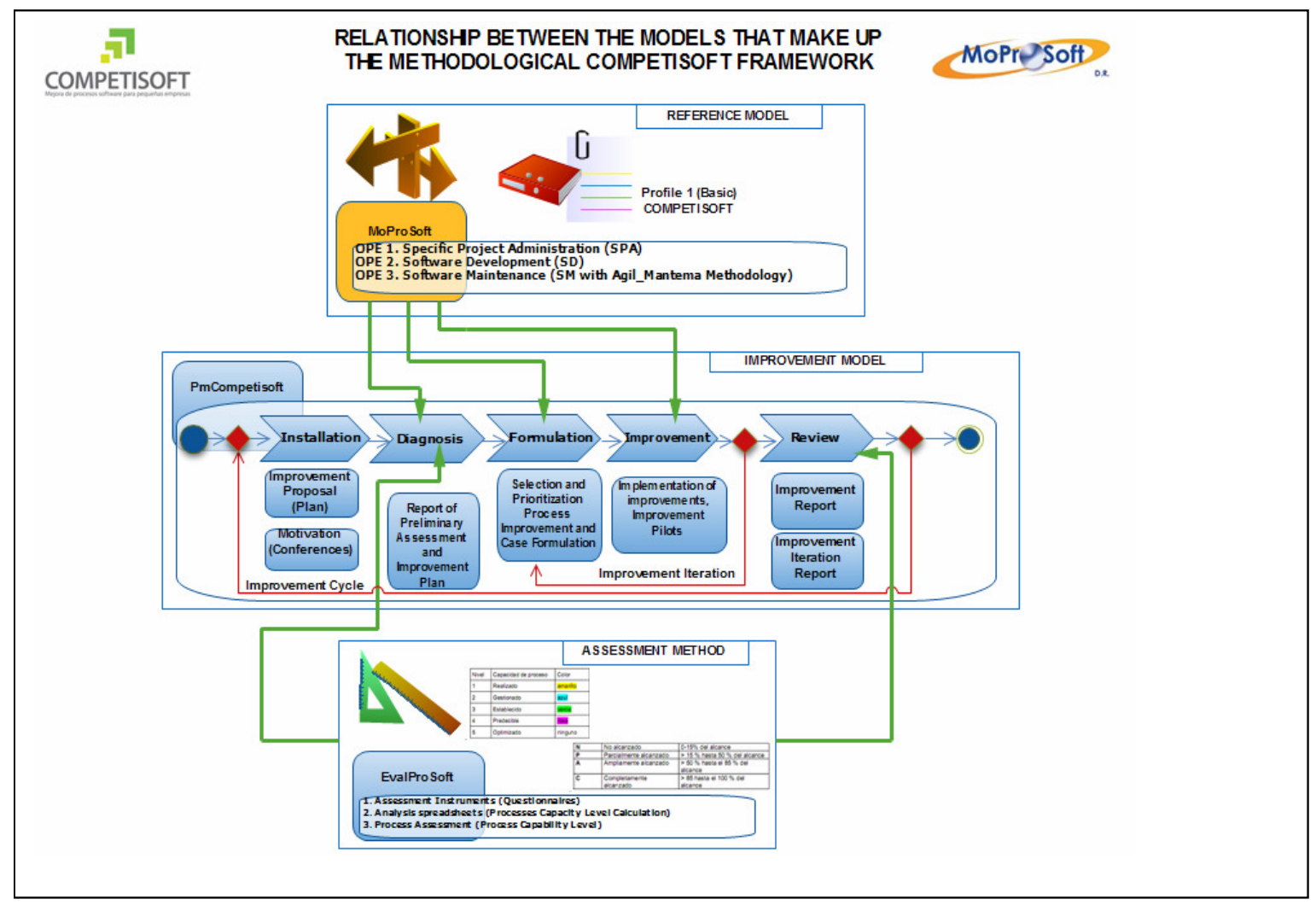

Figure 1: Competisoft Methodological Framework

The structure of this paper is presented as follows: the related works in Section 2, Competisoft components in Section 3, Tutelkan components in Section 4, the methodology used in Section 5, the results of the diagnosis and the implementation of the improvement cycle in Section 6, the results in Section 7, finishing with the conclusions in Section 8.

\section{RELATED WORKS}

The situation of process improvement in SMEs is a subject of special interest in the software engineering community, which is reflected by a significant increase in studies that deal with the issue and make reference to its trends [3] [6] [13]. Moreover, international organizations such as the SEI and the ISO are making efforts to bring their standards in software process improvement closer to small and medium-sized software companies. Some examples of note are the initiatives of the International Process Research Consortium (IPRC), part of the SEI, with the project Improving the Process in Small Settings (IPSS), and the formation of the SC7-WG24 work group by the 
ISO to address a common framework and which describes assessment profiles for life cycles in small companies. In the latter case the Basic Profile defined in MoProSoft [4] [5] has been considered an important contribution.

Local efforts for SMEs have emerged in order to address process reference models, models to guide improvements and process assessment methods: SIMEPAR-SW [11], Light MECPDS [14], MPS BR [18], MoProSoft [7], IMPACT [17], PmCompetisoft [16], MESOPyME [1], EvalProSoft [8], ADEPT [12], RAPID [2], PROCESSUS [10].

Applications of the Competisoft methodological framework have been developed at a controlled testing level, mainly in Spain, Argentina, Uruguay, Peru and Chile, in which some of our work is included [9]. Besides models and standards, technological support platforms for improvement models are being developed, such as the Tutelkan which is expected to create a mechanism that allows SMEs to formalize, define and document their software development processes and systems in order to achieve the continuous improvement of their processes, as well as certification if required.

\section{COMPETISOFT COMPONENTS}

The Competisoft process model is based on MoProSoft, which in turn considers the three basic categories of the structure of an organization and their own processes:

- Top Management, with the Business Management process.

- Middle Management, with the following processes: Process Management, Project Management and Resource Management.

- The Operation category, with its processes of: Specific Project Administration (SPA), Software Development (SD) and Software Maintenance (SM).

The processes of the Operation category are called the Basic Profile of Competisoft, since there is empirical evidence that the most important things to be improved by companies which possess a strategic plan are the processes involved in the Operation category. This profile was well received by the community that researches into the quality area (Group SC7-WG24) and was quickly requested by the ISO / IEC committee in order to be incorporated into its standard ISO / IEC 29110.

The Software Maintenance process is based on the Agil_MANTEMA methodology, which was created from the MANTEMA methodology for large organizations and from the agile Scrum method for project or service management [15]. Agil_MANTEMA is focused on smaller organizations and aims to define a maintenance process detailing what should be done, when, how and by whom, in other words, its aim is to give step by step guidance for the software maintenance process in this type of organization.

MoProSoft seeks to support organizations in the standardization of their practices, the assessment of their effectiveness and the incorporation of continuous improvement. It offers a consistent process pattern in a schema of elements that is useful for process documentation. It consists of three parts: Process Definition, Practices, and Tailoring Guidelines.

The process assessment model EvalProSoft can be used to obtain the capability profile of the implanted processes and a capability maturity level for the organization. The assessment is based on process requirements and on the process capability model. This model sets Capability Levels, Process Attributes and the following rating scale (see Table 1):

- N: Not achieved $(0-15 \%)$

- P: Partially achieved (greater than $15 \%$ to $50 \%$ )

- A or L: Largely achieved (greater than $50 \%$ to $85 \%$ )

- C or F: Fully achieved (greater than $85 \%$ to $100 \%$ )

Table 1: Qualification of the process capability level

\begin{tabular}{lllllll}
\hline $\begin{array}{l}\text { Level } \\
\text { Attributes }\end{array}$ & $\mathbf{1}$ & $\mathbf{2}$ & $\mathbf{3}$ & $\mathbf{4}$ & $\mathbf{5}$ \\
\hline 1.1 Process Performance & A & C & C & C & C \\
2.1 Performance Management & - & A & C & C & C \\
2.2 Work Product Management & - & A & C & C & C \\
3.1 Process Definition & - & - & A & C & C \\
3.2 Process Deployment & - & - & A & C & C \\
\hline
\end{tabular}




\begin{tabular}{lccccc}
\hline 4.1 Process Measurement & - & - & - & A & C \\
4.2 Process Control & - & - & - & A & C \\
5.1 Process Innovation & - & - & - & - & $\mathbf{A}$ \\
5.2 Process Optimization & - & - & - & - & $\mathbf{A}$ \\
\hline
\end{tabular}

Process capability is evaluated on a scale from 0 to 5 . The value 0 is associated to the lowest capability level and means that the purpose of the process is not achieved. The value 5 is associated to the highest level of capability and means that the current business goals and those projected through optimization and continuous process improvement are achieved. Capability is measured through a set of process attributes, which are used to determine when a process has reached a certain capability. Each attribute measures a particular aspect of a process.

PmCompetisoft is a process that guides the execution of a cycle of software process improvement in small and medium-sized enterprises. It is characterized for being sufficiently light to be put into practice by SME software manufacturers. PmCompetisoft cycles consist of 5 macro-activities: Installation, Diagnosis, Design, Improvement and Program Review. PmCompetisoft is an iterative and incremental process organized through improvement miniprojects which include cases of improvement within an overall improvement program, as shown in Figure 2.

Improvement iteration is an improvement mini-cycle that allows progress to be made in the development and management of a set of improvement cases in an independent way. This gives visibility to the improvement project.

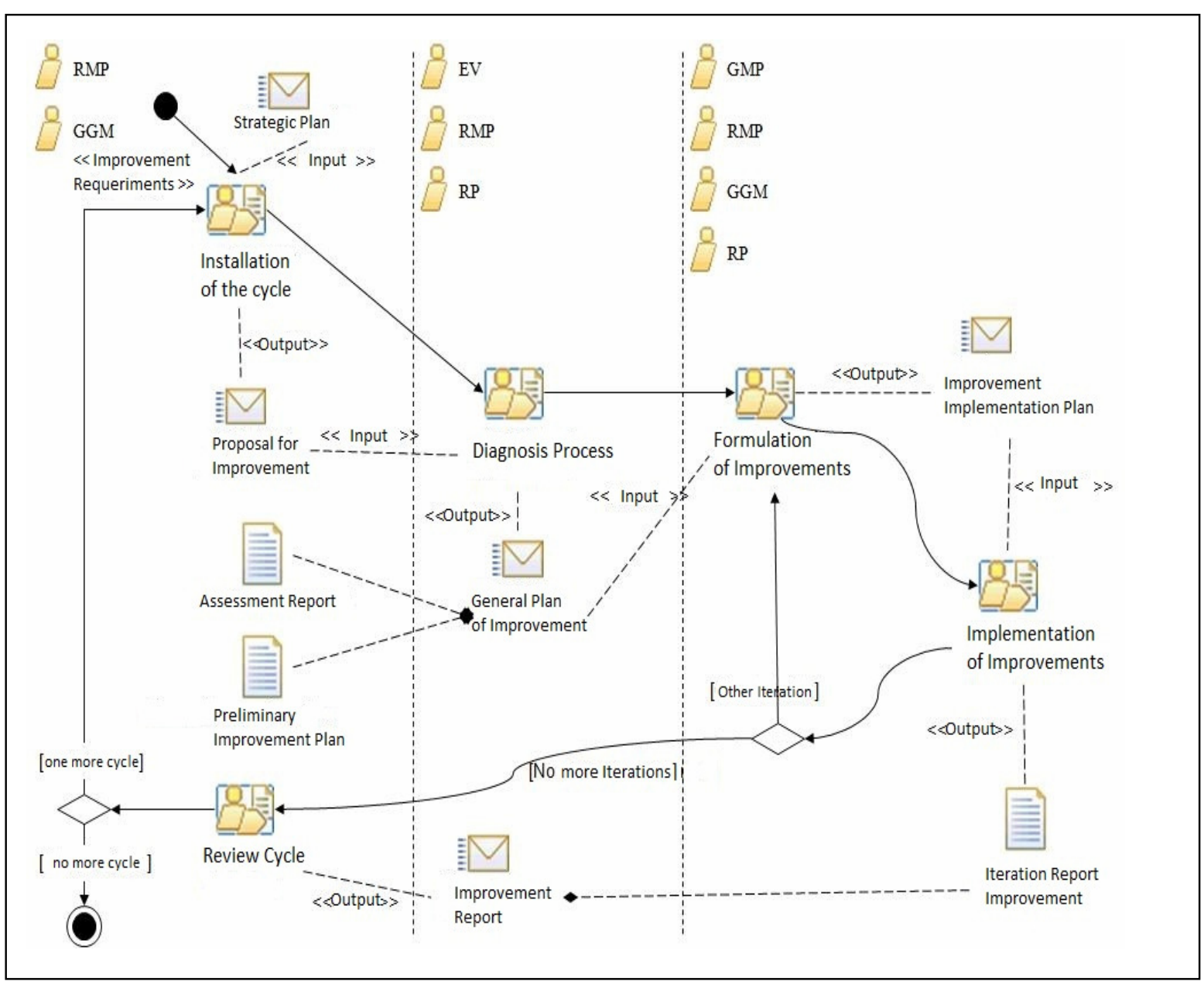

Figure 2: PmCompetisoft Workflow 


\section{TUTELKAN COMPONENTS}

Tutelkan is a public interest project that seeks to support SMEs that export software, backing them in the certification of their processes, and ultimately, in the improvement of their opportunities. It is an innovative system based on Open Source technology and it is free, as the idea is that in the long term they can give and receive feedback, using references and good practices already in use. The platform aims to impact socioeconomic development in Chile in a positive way. Among its benefits are: helping software development companies to improve their productivity and the quality of what they do; optimizing the export of software and services, and also generating a critical mass of experts in quality improvement.

Tutelkan consists of the following elements:

- Tutelkan Implementation Process (TIP), which corresponds to the process of implementing the Tutelkan processes so that SMEs can adapt and adopt processes with the help of experts.

- Tutelkan Process Framework (TPF), which is the metamodel of Tutelkan software processes and defines what types of processing elements are valid and which relationships among these elements are permissible.

- Tutelkan Reference Process (TRP), which corresponds to the Tutelkan reference process and defines a particular software process whose parts can be reused and modified to create new software processes.

- Tutelkan Web Platform (TWP), which includes web tools and permits the exploration and collaborative production of public software processes, and also the development of public software processes that reuse the elements of public processes that satisfy the CMMI model.

Furthermore, the platform uses transfer flows to transfer knowledge on a software process directly to people or to a company (see Figure 3). The following may be used:

- Autonomous transfer flow: There is an individual exploration, that is to say, people who want to expand their knowledge.

- Guided transfer flow: For diagnosis, implementation and monitoring guided by experts. This is designed for companies that want to implement improvements.

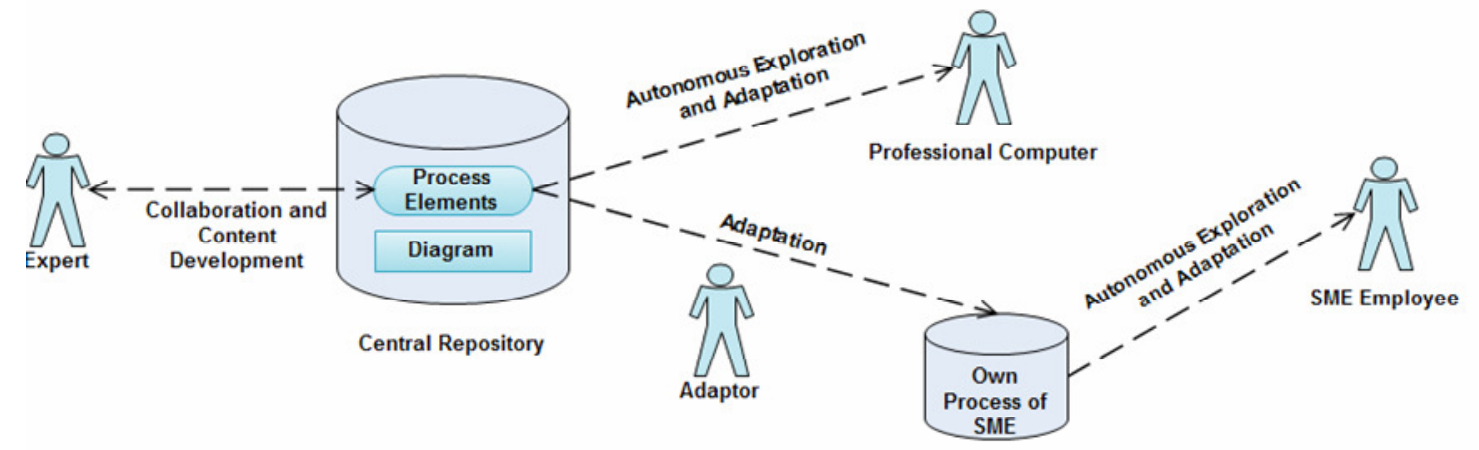

Figure 3: Tutelkan Transfer Flow

\section{METHODOLOGY}

The main activities carried out in this research are the following:

\subsection{Research on theory and studies supporting this exploratory research.}

Review and analysis of bibliographical material on the Competisoft methodological framework and models that form part of it and study of the Agil_MANTEMA methodology and the Tutelkan platform. This was done to acquire the necessary knowledge and skills for implementing the software improvement process in the company, based on the theory and concepts from the bibliographical material that was reviewed. 


\subsection{Initial meetings with the company}

Presentation of the project (improvement cycle of software processes) and the Competisoft framework to the Head of the Software Area at the company, which included the development of a working proposal, so as to gain the commitment and support of the managerial department and the staff in the area for the initiation of the cycle.

\subsection{Incorporation of the Competisoft basic profile into Tutelkan}

Entering information about the pattern of each process of the Competisoft basic profile into the virtual platform (see Figure 4).

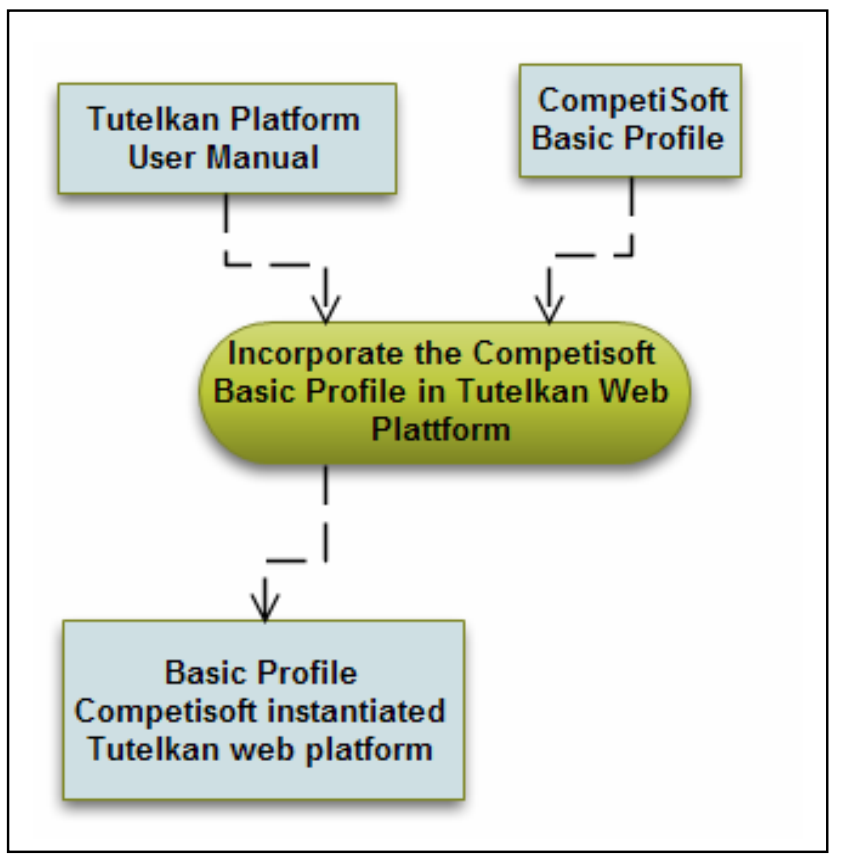

Figure 4: Integrating basic profile into Tutelkan.

This activity includes the following tasks:

- Learning stage on the usability of the platform (creation of processes; creation of process elements: activities, tasks, work products, roles; linkages between the elements of processes).

- Instantiating of the processes of Specific Project Administration, Software Development and Software Maintenance.

\subsection{Implementation of the Improvement Cycle}

This includes monitoring the macro-activities of the model, the incorporation of most of the artifacts from the Competisoft basic profile (generated or improved) into Tutelkan and the creation of a Knowledge Base specific to the software area of the company. The sub-activities are associated to the development of the following activities:

- Installation: In the initial meetings the Head of the Technological Division of the Company receives information on concepts of software quality, process improvement and how the Competisoft methodological framework fits the reality of SMEs involved in the improvement of software processes; the objectives of the framework are explained as well as its main features and benefits. Subsequently, and with the consent of the area, the development of an improvement proposal is worked out (Working Plan).

- Initial Diagnosis: The method for assessing EvalProSoft processes is followed. Thus, assessment instruments are developed: questionnaires for each process of the basic profile, separated by the capability levels of the attributes that make up each process (level 1 and level 2). These questionnaires are created on the basis of the general definition and practices of the processes of the MoProSoft model (basic profile) and the Agil_MANTEMA methodology (for the maintenance process). 
- Formulation: According to the results obtained from the evaluation performed in the Diagnosis activity, higher priority improvement cases are taken and the improvement iterations are planned in a meeting with the department heads, with the aim of estimating the effort and time of the cycle. A record of this information is detailed on a document named Improvement Implementation Plan.

- Enhancement: To carry out activities to improve the processes of Specific Project Administration and Software Development, the process pattern of the MoProSoft model was used. In the case of software maintenance the pattern of the Agil_MANTEMA methodology was followed.

- Review: At the end of each improvement iteration a record is made of the improvement that is achieved in the attribute of the process that has been improved. This information is stored in the Knowledge Base created for the company during the improvement cycle. A final assessment is performed to compare the level of initial capability versus the level reached at the end of the improvement cycle using the same instruments of assessment. The steps used for the assessment of the final processes are the same as for the initial diagnosis and for the assessment questionnaires (level 1 and level 2).

\subsection{Closing the Project}

This involves collecting the lessons that have been learned and suggestions for improving the project, delivering a final report with the results of improvement per process and attribute, and the conclusions of the improvement cycle; this marks the completion of the project.

\section{RESULTS OF THE DIAGNOSIS AND IMPLEMENTATION OF THE IMPROVEMENT CYCLE}

Table 2 shows the results of the basic profile processes obtained per attribute once the initial diagnosis had been completed. The table shows the percentage of activities defined by the Competisoft process model. Moreover, the qualitative analysis identifies the relationship and connection between the activities of the three basic profile processes with the roles that exist within the organization, the work products and the available tools, used in the organization at the time of the diagnosis. These facts have been included in a table of strengths and improvement opportunities for each process.

Table 2: Initial assessment of the quantitative analysis

\begin{tabular}{ccccc}
\hline $\begin{array}{c}\text { Basic Profile } \\
\text { Process }\end{array}$ & $\begin{array}{c}\text { Process } \\
\text { Performance }\end{array}$ & $\begin{array}{c}\text { Performance } \\
\text { Management }\end{array}$ & $\begin{array}{c}\text { Work Product } \\
\text { Management }\end{array}$ & $\begin{array}{c}\text { Capability } \\
\text { level }\end{array}$ \\
\hline SPA & $59,65 \%$ & $50 \%$ & $37,5 \%$ & 1 \\
SD & $48,1 \%$ & $20 \%$ & $17,57 \%$ & 0 \\
SM & $66,32 \%$ & $75 \%$ & $65 \%$ & 1 \\
\hline
\end{tabular}

Among the most significant improvement opportunities identified in the company are:

- Information about projects is mostly handled informally.

- There is no protocol for the preparation of user manuals.

- Non-performance of some analysis and design activities, such as defining the architecture of the system and conceptual modeling.

- There is no distinction between the types of maintenance to be performed.

Table 3 shows the results of the basic profile processes obtained per attribute in the final assessment, along with the level of capability of the processes.

Table 3: Final evaluation of the quantitative analysis

\begin{tabular}{ccccc}
\hline $\begin{array}{c}\text { Basic Profile } \\
\text { Process }\end{array}$ & $\begin{array}{c}\text { Process } \\
\text { Performance }\end{array}$ & $\begin{array}{c}\text { Performance } \\
\text { Management }\end{array}$ & $\begin{array}{c}\text { Work Product } \\
\text { Management }\end{array}$ & $\begin{array}{c}\text { Capability } \\
\text { level }\end{array}$ \\
\hline SPA & $84,21 \%$ & $87,5 \%$ & $41,67 \%$ & 1 \\
SD & $84,01 \%$ & $84 \%$ & $20,27 \%$ & 1 \\
SM & $85,26 \%$ & $75 \%$ & $65 \%$ & 2 \\
\hline
\end{tabular}


The analysis of the outcome of each attribute per process is as follows:

Specific Project Administration Process:

- The Process Performance attribute is Largely Achieved.

- The Performance Management attribute is Fully Achieved.

- The Work Product Management attribute is Partially Achieved.

Software Development Process:

- The Process Performance attribute is Largely Achieved.

- The Performance Management attribute is Largely Achieved.

- The Work Product Management attribute is Partially Achieved.

Software Maintenance Process:

- The Process Performance attribute is Fully Achieved.

- The Performance Management attribute is Largely Achieved.

- The Work Product Management attribute is Largely Achieved.

As can be seen in Table 3, the Software Maintenance Process (SM) reached level 2 (Managed), demonstrating the highest level of capability among the three evaluated processes.

\section{ACHIEVEMENTS IN THE IMPLEMENTATION OF AN IMPROVEMENT CYCLE}

The following gives a brief overview of the major achievements of the company, as identified with the improvement leaders for each process during the improvement cycle and its iterations.

\subsection{Iteration I: Software Development (SD) Process}

With regard to Software Development (SD) the following improvements were achieved:

- The roles to be performed by the people involved in the process and the activities and tasks to be achieved were identified, leading as a result to a set of artifacts for each: documents, manuals, plans, reports, models, as well as the software, so as to obtain better quality products that meet the expectations and needs of the customers and users from other areas of the organization.

- Emphasis was mainly placed on institutionalizing the Analysis and Design phase, which is essential to develop better quality software in accordance with functional and nonfunctional requirements. UML was used to support the implementation of this phase.

- Templates and guidelines were developed and they contributed to the creation of the necessary documents for the process.

- Programming norms and standards were defined and improvements were made in the documents necessary to plan, execute and record evidence (plans, test cases, reports).

- The user became more involved throughout the development cycle, from the requirements stage to the end of the development project. In fact, documents of approval (which are called certification, pre-production and post-production) must be filled in and signed before the product is delivered or is available on the intranet.

- The information about each project, and the general one, will be available on the Knowledge Base pertaining to the area.

\subsection{Iteration II: Specific Project Administration (SPA) Process}

With regard to the Specific Project Administration (SPA), the following improvements were achieved:

- The roles to be performed by the people involved in the process and the activities and tasks to be achieved were identified, leading as a result to a set of artifacts for each: documents, manuals, plans, reports, models, and surveys. 
- Emphasis was mainly placed on institutionalizing documents that allow better management of both development projects and software maintenance projects.

- A formalization of the use of documents. Before the SD requirements phase, users must fill in the Project Description which is the starting point of the SPA process and gives the first approach to the product that is to be developed.

- Templates and guidelines were established in order to facilitate the creation of the documents necessary for the process.

- Emphasis was placed on improving communication between the various areas involved in a project, this was done by developing communication plans, in which areas, tools and communication channels are clearly defined.

- The two documents, Project Plan and Development Plan, which are necessary to guide and conduct Development and Maintenance projects, will be gradually implemented in new projects. The same will happen with the Project Monitoring Report which will mediate progress, goal achievement and effort estimation so as to be clearer in setting the start and end dates of any projects in the area.

- Project management tools like MS Project and G-Force and the Tutelkan platform will enable better quality planning, reporting and controlling of the three processes and the activities and tasks of the development and maintenance projects performed by the team.

- Information on each project, and the general one, will be available on the Knowledge Base of the area.

\subsection{Iteration III: Software Maintenance (SM) Process}

With respect to Software Maintenance (SM) the following improvements were achieved:

- The roles to be performed by the people involved in this process were identified according to the Agil_MANTEMA methodology, as were the activities and tasks that must be achieved, leading, as a result, to a set of artifacts for each (see Figure 5): documents, manuals, plans, reports, as well as the software that has been corrected, improved or adapted in order to meet the new expectations and needs of customers and users from other areas of the organization who demand changes in the products.

- Templates and guidelines were established in order to facilitate the creation of documents necessary for the process.

- Emphasis was mainly placed on institutionalizing new phases, such as Care, Analysis of Requirement Applications, etc., where the form will be received and the type of maintenance to be applied will be defined according to the amendment request.

- In many cases there will be diagnosis of the error or amendment, and possible solutions will be proposed to carry out the modification of the software based on the type of maintenance.

- Regular meetings will be held during the Maintenance Cycle where the team will meet to support the project and discuss what has been done.

- Documents to execute and record the tests were improved (test cases and test report). A withdrawal plan before the leaving of the old software will also be previously defined.

- As in the Development phase, the aim is to engage the customer and the user throughout a large part of the process. In fact, approval documents (which are called certification, pre-production and post-production) must be filled in and signed before the maintained product is delivered or the updated version is available on the intranet.

- Information on each project, and the general one, will be available on the Knowledge Base of the area.

\section{CONCLUSIONS}

It can be seen that the implementation of quality models aimed at SMEs is a good starting point if the way to continuous process improvement and certification under international quality standards is to be sought. Projects like Competisoft deliver the basic elements to formalize and institutionalize processes in an organization according to a Knowledge Base. Furthermore, the Tutelkan web platform is a good complement to achieving this goal, since among other things it allows the instantiation of quality models, reference processes, and the company's own 
software and projects as well. Thus, in order that the organization's staff who use the tool accelerate their understanding, the Tutelkan web platform was used before and during the execution of the improvement cycle on the basic profile processes of the company, using all their documentation.

One of the advantages of the Tutelkan platform which is of note is that once all the processes have been instantiated, it delivers better visibility on the elements of a process at the moment of consulting them.

Strategies such as the appointment of process leaders, bulletins, process maps and traceability matrices also greatly supported the improvement process. During the development of the improvement cycle, an initial Knowledge Base arose for the specific software area. Here, the lessons that were learned are considered but also the information obtained from each process which thus gives continuity over time.

The Agil_MANTEMA methodology was rapidly tailored to the current working methods of the software area, since it covers most of the roles, activities and tasks of the process, so the emphasis on the improvement was more frequent in the formalization of the documentation.

The support, field work and constant motivation of the Competisoft improvement team from the software area of the company was essential for the success of this study, due to the limited availability of staff time throughout the duration of the improvement cycle. This shows that the way to continuous improvement requires discipline, commitment and perseverance.

As a future study, we aim to incorporate Competisoft complete models and methods to the Tutelkan web platform in order to make it into another reference model for companies that wish to begin process improvement and to be able to include a Knowledge Base with the artifacts that are generated in the company.

\section{Acknowledgements}

Special thanks to the Tutelkan Project (CORFO project online innovation of public interest: 05CR11 II-21) and the company Oriencoop Ltd. and its area of Division and Technology, where the process improvement cycle in which this research is based on took place

\section{References}

[1] J. A. Calvo-Manzano, G. Cuevas, T. San Feliú, A. De Amescu, M Pérez, Experiences in the application of software process improvement in SMES, Software Quality Control, v.10, issue.3, pp. 261-273, november2002.

[2] A. Cater-Steel, M. Toleman, T. Rout, Process improvement for smalls firms. An evaluation of the RAPID assessment-based method. Information and Software Technology, Vol 48, issue 5, 2006, pp. 323-334 .

[3] K. Coleman, P. Larsen, M. Shaw, M. Zelkowitz, Software Process Improvement in Small Organizations: a Case Study. IEEE Software, November/December 2005, pp 68-75.

[4] G. Fernández, J. Triñanes, Modelo de Mejora de Procesos de Software para PyMEs 29110. 2008 (in spanish). http://www.asiap.org/JIAP2008/PDF/115-UNIT.pdf

[5] M. Garcia, J. Garzás, M. Piattini, La Mejora de Procesos en Pequeñas Empresas y la ISO/IEC 29110 (in spanish)

http://kybeleconsulting.com/downloads.com/downloads/MCGarcia_MejoraProcesos_ISO29110.pdf

[6] C. Gresse, S. Weber, J. C. Rossa, G. Trentin, Experiences on establishing software process in small companies. Information and Software Technology, v. 48 issue 9, 2006, pp. 890-900.

[7] H. Oktaba, MoProSoft: A Software Process Model for Small Enterprises, Proceedings 1st International Research Workshop for Process Improvement in Small Settings, Special Report CMU/SEI-2006-SR-001, Software Engineering Institute, 2006, pp. 93-101.

[8] H. Oktaba, C. Alquicira, A. Su Ramos, J. Palacios, C. Pérez, F. López, EvalProSoft Versión 1.1, Technical Report, 2004 (in spanish).

[9] H. Oktaba, F. García, M. Piattini, F. Ruiz, F. Pino, C. Alquicira, Software Process Improvement: The Competisoft Project. Computer, IEEE Computer Society, October 2007, pp. 21-28.

[10] R. V. Horvat, I. Rozman, J. Györkös, Managing the complexity of SPI in small companies". Software Process: Improvement and Practice, vol 5(1), march 2000, pp. 45-54..

[11] J. A. Hurtado, C. Bastarrica, Hacia una línea de procesos ágiles Agile SPsL. Research Work SIMEP-SW, ver 1.0, U. del Cauca, Colombia . 2005.

[12] M. McCaffery, I. Richardson, G. Coleman, Adept - A Software Process Appraisal Method for Small to Medium-Sized Irish Software Development Organizations, Europen Systems \& Software Process Improvement and Innovation (EuroSPI 2006), Finland, pp. 7.12-7.21

[13] F. Pino, G. García, M. Piattini, Revisión sistemática de mejora de procesos software en micro, pequeñas y medianas empresas. Revista española de Innovación, Calidad e Ingeniería de Software (REICIS), vol 2(1), april 
2006, pp 6-23 (in spanish).

[14] F. Pino, G. García, F. Ruiz, M. Piattini, Adaptación de las normas ISO/IEC 12207: 2002 e ISO/IEC 15504:2003 para la evaluación de de la madurez de procesos software en países en desarrollo. JISBD 2005, Granada, España, 2005, pp. 187-194 (in spanish).

[15] F. Pino, F. Ruiz, S. Salas, COMPETISOFT: Agil_MANTEMA v1.0, Technical Report, 2008 (in spanish).

[16] F. Pino, J. C. Vidal, F. García, M. Piattini, Modelo para la Implementación de Mejora de Procesos en Pequeñas Organizaciones Software, 2007 (in spanish).

[17] L. Scott, R. Jeffery, L. Carvallo, J. D’Ambra, P. Rutherford, Practical Software Process Improvement - The IMPACT project, Proceedings of the 13th Australian Software Engineering Conference (ASWEC'01), 2001.

[18] K. Weber, E. Araújo, A. Rocha, Machado, D. Scalet, C. Salviano, Brazilian Software Process Reference Model and Assessment Method. Comnputer and Information Sciences. Springer Berlin/heidelberg,, 2005, pp. 402-411 